\title{
Simulação da Prioridade de uso das Águas Superficiais como um Critério para o Instrumento da Outorga
}

\author{
Maria Adriana de Freitas Mágero Ribeiro*, Dayse Luna Barbosa*, Marcondes Loureiro de Carvalho Batista*, \\ José do Patrocínio Tomaz Albuquerque*, Márcia Araújo de Almeida*, Márcia Maria Rios Ribeiro* \\ drickadefreitas@yahoo.com.br,dayseluna@yahoo.com.br,marcondesloureiro@gmail.com,patrociniotomaz@uol.com.br, \\ marciaaraujo@yahoo.com,mm-ribeiro@uol.com.br
}

Recebido: 17/05/12 - revisado: 11/03/13 - aceito: 14/01/14

\section{RESUMO}

A utilização da água subterrânea tem se tornado cada vez mais frequente nos grandes centros urbanos. Os órgãos gestores de recursos hídricos têm se preocupado em implementar mecanismos de controle que possam impor o uso racional desse recurso. Este trabalho apresenta uma simulação que considera a prioridade de uso das águas superficiais como um critério para a outorga. Aplicação é feita para a Bacia Sedimentar Costeira da Região do Baixo Curso do rio Paraíba e para a Bacia do rio Gramame, ambas no Estado da Paraíba. As potencialidades e disponibilidades das águas superficiais são observadas a fim de auxiliar o órgão gestor na concessão das outorgas de direito de uso das águas superficiais. Segundo o critério adotado, o uso das águas superficiais é considerado prioritário em relação ao uso das águas subterrâneas - consideradas estratégicas, devendo ser utilizadas apenas quando não houver a alternativa de suprimento hidrico superficial.

Palavras-Chave: Outorga de direito de uso da água; água subterrânea; gestão integrada de recursos hídricos.

\section{INTRODUÇÃOO}

A Lei Federal 9.433/97 que instituiu a Política Nacional de Recursos Hídricos estabeleceu como um de seus instrumentos a Outorga de Direito de Uso de Recursos Hídricos. Definida como um instrumento em que o poder público confere o direito de uso do recurso a um ente público ou privado, analisando a quantidade, qualidade, a finalidade de uso e o tempo para o uso, a outorga tem sido considerada como um instrumento fundamental de gestão por depender da disponibilidade hídrica, temporalmente e espacialmente na bacia hidrográfica e das necessidades para a conservação dos sistemas hídricos (FRANTZ e CRUZ, 2010; CRUZ e TUCCI, 2005).

Diante das diversas finalidades da água, há, muitas vezes, conflitos gerados entre setores usuários. Assim, é fundamental a gestão e regulação dos recursos hídricos tornando sustentáveis as demandas econômicas, sociais e ambientais por água, com o objetivo de permitir uma relação de harmonia entre

*Programa de Pós Graduação em Recursos Naturais e Programa de Pós Graduação em Engenharia Civil e Ambiental - Universidade Federal de Campina Grande os usos atuais e futuros evitando conflitos de uso. Por isso, a outorga é essencial, pois ordenando e regularizando o uso da água é possível assegurar ao usuário o efetivo acesso a ela, bem como realizar o controle quantitativo e qualitativo dos usos da água.

No Estado da Paraíba, o Decreto 19.260/97, que regulamenta a outorga, traz como critérios condicionantes para esse instrumento: a disponibilidade hídrica, as prioridades de uso, a comprovação de que o uso de água não cause poluição ou desperdício dos recursos hídricos. No Decreto considera-se que a soma dos volumes de água outorgados em uma determinada bacia não poderá exceder 9/10 da vazão regularizada anual com $90 \%$ de garantia.

Nesta pesquisa verifica-se que um dos critérios propostos, a ser acrescentado aos critérios já dispostos no Decreto Estadual, é o critério de prioridade de uso das águas superficiais. Este artigo tem por objetivo simular o critério prioridade de uso da água superficial para duas bacias litorâneas no Estado da Paraíba, tendo por justificativa que o uso da água subterrânea, estratégico, só deverá acontecer quando não for possível o suprimento a partir dos recursos hídricos superficiais. 


\section{A outorga no âmbito Estadual}

No âmbito estadual, a Política de Recursos Hídricos da Paraíba foi instituída pela Lei 6.308/96, alterada pela Lei 8.446/07, sendo determinado que a outorga é um dos instrumentos de gerenciamento dos recursos hídricos. Cabe ao Conselho Estadual de Recursos Hídricos estabelecer critérios gerais para a outorga e deliberar sobre as acumulações, derivações, captações e lançamentos de pouca expressão, para efeito de isenção da obrigatoriedade de outorga de direitos de uso da água, com base nas propostas apresentadas pelos Comitês de Bacia Hidrográfica.

O Decreto 19.260/97, já comentado, regulamenta a outorga do direito do uso dos recursos hídricos estabelecendo que para atender o procedimento da outorga, os seguintes princípios gerais devem ser observados: i) a água constitui direito de todos para as primeiras necessidades da vida; ii) o uso da água tem função social com prioridade para o abastecimento humano; iii) é dever de toda pessoa, física ou jurídica, zelar pela preservação dos recursos hídricos nos seus aspectos de qualidade e de quantidade; iv) será dada prioridade para o aproveitamento social e econômico da água, inclusive como instrumento de combate à disparidade regional e à pobreza nas regiões sujeitas a secas periódicas; v) o uso da água será compatibilizado com as políticas de desenvolvimento urbano e agrícola.

\section{METODOLOGIA}

\section{Critérios de outorga para as águas subterrâneas}

Em ASUB (2010) e Costa et al. (2011) foram propostos os seguintes critérios de outorga para as águas subterrâneas: prioridade de uso das águas superficiais, potencial de água subterrânea, qualidade de água, prioridades de uso, intrusão salina, vulnerabilidade de aquíferos, interferência entre poços, rebaixamentos máximos permissíveis e gestão da demanda.

O critério de prioridade de uso das águas superficiais - simulado nesta pesquisa - propõe a consideração do uso dos recursos hídricos superficiais como prioritários em relação ao uso dos recursos hídricos subterrâneos, uma vez que estes últimos são considerados recursos estratégicos, devendo ser utilizados quando não houver alternativa. Os recursos hídricos subterrâneos são estratégicos por responderem pela perenização dos cursos d'água fluviais, e pela manutenção das condições de umidade das zonas do solo e de subsaturação, através dos quais suprem a demanda ecológica natural do meio ambiente, especialmente no período de estiagem, o que deve ser preservado.

Faz-se necessário que o órgão gestor possua o conhecimento da disponibilidade hídrica superficial, determinada pelos volumes dos reservatórios disponíveis na área em que se deseja a outorga e definida pela vazão de regularização dos açudes com tal condição. Existindo essa alternativa de suprimento de água na região, com disponibilidade para atendimento com um nível tolerável de garantia, o usuário ficaria impossibilitado de ser atendido em seu pedido de outorga pela captação de água subterrânea.

A consideração deste critério como prioritário resulta, também, do fato de que as águas subterrâneas devem ser vistas como um recurso renovável, com recarga, escoamento e descarga e, não, como uma reserva ou estoque de recursos hídricos em si mesma. A reserva é importante, sim, mas como viabilizadora do escoamento da água subterrânea de aquíferos que, recarregados, circula e é descarregada na rede hidrográfica sobre ou adjacente, no solo (através das fontes), na zona de subsaturação e no oceano, entre outros exutórios naturais e artificiais. No caso dos rios (águas ditas superficiais), o escoamento das águas subterrâneas vai constituir o seu fluxo de base, responsável pela perenização desses cursos d'água superficiais. Esse regime de escoamento natural deve, inicialmente, ser mantido, já que a sua exploração, seja por captações diretas ("a fio d'água”), seja por indiretas (o fluxo de base responde às explotações por poços, reduzindo e, até, anulando a sua vazão) indubitavelmente conduz à alteração desse regime. As consequências desta opção são: o definhamento (seguida de extinção) dos ecossistemas ribeirinhos, o impedimento da navegabilidade e, nas áreas mais afastadas do leito desses rios (interflúvios), ocorrerá o aprofundamento da franja capilar de aquíferos livres, restringindo o vigor da vegetação que se alimenta, nos períodos de exclusividade do fluxo de base, da umidade da zona de sub-saturação, suprida pela capilaridade da superfície hidrostática desses aquíferos.

Porém, alguns fatores devem ser considerados, como por exemplo, a situação financeira do usuário e a localização do usuário de água, pois se o manancial superficial (reservatório) encontra-se muito distante do local que será utilizada a água, a adução pode tornar a captação mais cara do que a perfuração de um poço próximo ou a captação a fio d'água e, desta forma, a relação custo-benefício poderá ser prejudicada. No estado da Paraíba, o 


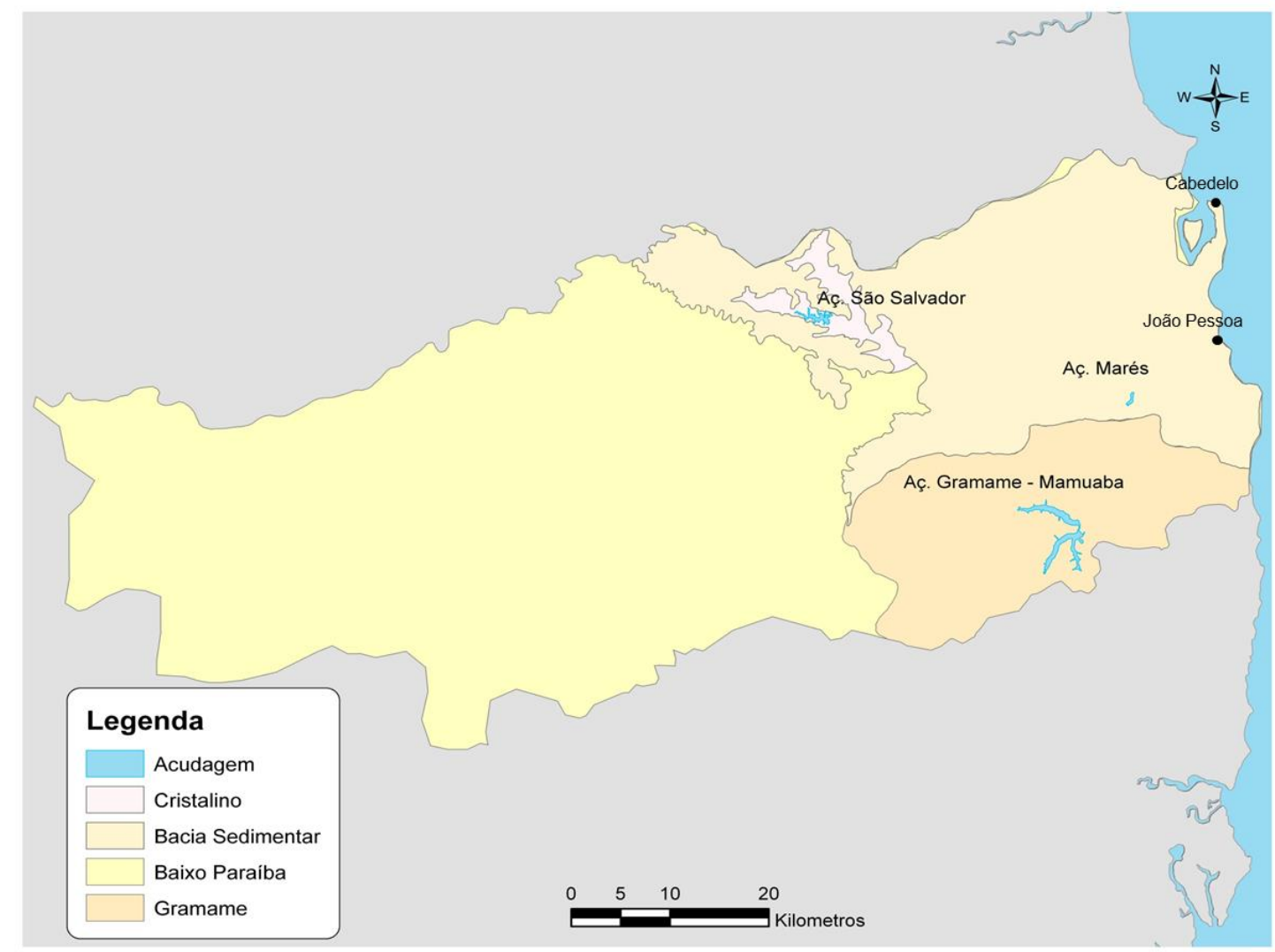

Figura 1 - Localização da Bacia Sedimentar Costeira Paraíba-Pernambuco pertencente à Região do Baixo Curso do rio Paraíba e Bacia do Gramame - Paraíba (área de estudo).

critério de prioridade de uso das águas superficiais não é adotado para emissão de outorga.

\section{Área de estudo}

A aplicação do critério em foco é feita para uma área de 1.698,07 $\mathrm{km}^{2}$, compreendendo a porção da Bacia Sedimentar Costeira PernambucoParaíba inserida na Região do Baixo Curso do rio Paraíba $\left(1.108,69 \mathrm{~km}^{2}\right)$ e a Bacia Hidrográfica do rio Gramame $\left(589,38 \mathrm{~km}^{2}\right)$ (Figura 1).

Os reservatórios adotados para efeito de simulação são os de maior relevância para a região. São eles: o sistema de reservatórios GramameMamuaba, localizado na Bacia do rio Gramame; os reservatórios Marés e São Salvador inseridos na porção da Bacia Sedimentar Costeira PernambucoParaíba da Região do Baixo Curso do rio Paraíba.

A cidade de João Pessoa apesar de estar situada na Região do Baixo Curso do rio Paraíba, é abastecida pelas águas do sistema Gramame-
Mamuaba e pelo reservatório de Marés, sendo o valor de captação de $1,90 \mathrm{~m}^{3} / \mathrm{s}$ e $0,90 \mathrm{~m}^{3} / \mathrm{s}$ respectivamente. A barragem Gramame-Mamuaba foi construída na Bacia Hidrográfica do rio Gramame em 1999 e possui capacidade para armazenar 56,9 milhões de $\mathrm{m}^{3}$ de água. A vazão de regularização do sistema Gramame-Mamuaba é de 2,45 $\mathrm{m}^{3} / \mathrm{s}$ com $100 \%$ de garantia. O reservatório Marés, situado na Região do Baixo Curso do rio Paraíba, teve sua construção concluída em 1951, com a finalidade de abastecimento humano (FONSECA, 2008). A vazão regularizada do reservatório Marés é de $0,222 \mathrm{~m}^{3} / \mathrm{s}$ com $100 \%$ de garantia, calculada pelo modelo Acquanet (PORTO et al., 2003), com base na série de vazões utilizadas nos estudos do Plano Estadual de Recursos Hídricos (PARAÍBA, 2006). Entretanto, para complementar a vazão captada neste açude $\left(0,90 \mathrm{~m}^{3} / \mathrm{s}\right)$, é bombeado para ele água bruta do sistema Gramame-Mamuaba $\left(0,350 \mathrm{~m}^{3} / \mathrm{s}\right)$ e do rio Mumbaba $\left(0,450 \mathrm{~m}^{3} / \mathrm{s}\right)$, conforme informações da 
Companhia de Água e Esgotos do Estado da Paraíba (CAGEPA, 2011).

Durante os anos de 1997 a 1999, a Região Metropolitana de João Pessoa sofreu os efeitos adversos do fenômeno das secas, que foram marcados por dois anos seguidos de forte estiagem (SEMARH, 2000). O resultado dessa crise no abastecimento d'água culminou com o quase colapso do sistema Gramame-Mamuaba, o que não ocorreu devido às contribuições do fluxo de base proveniente do sistema aquífero Pernambuco-Paraíba. Para atendimento da demanda foi, estrategicamente, providenciada a perfuração de novos poços tubulares, principalmente em áreas urbanizadas.

O açude São Salvador, também localizado na Região do Baixo Curso do rio Paraíba, foi construído entre 1995 e 1997 e possui capacidade para acumular $12.657 .520 \mathrm{~m}^{3}$ de água. A bacia hidrográfica do açude é de $62,45 \mathrm{~km}^{2}$ e regulariza uma vazão de $0,054 \mathrm{~m}^{3} / \mathrm{s}$.

\section{Determinação da oferta e da demanda hídrica na região em estudo}

As caracterizações da oferta (potencialidade e disponibilidade) e da demanda de água na área de estudo são importantes para o cálculo da vazão máxima outorgável, sendo esta variável essencial para a simulação do critério ora estudado.

De acordo com o Plano Estadual de Recursos Hídricos - PERH (PARAÍBA, 2006) define-se potencial fluvial como a vazão natural anual média de longo período de um rio ou aquífero, medida ou gerada, em sua foz ou embocadura, ou em um ponto qualquer de seu curso, controlado por postos ou estações hidrométricas.

A disponibilidade hídrica constitui a parcela da potencialidade ativada pela ação do homem para o seu aproveitamento. No caso das disponibilidades de água subterrânea, estas são iguais à diferença entre o seu potencial e as demandas naturais, aí incluídas as perdas por evaporação, com todas essas variáveis quantificadas em termos de vazão (ALBUQUERQUE e RÊGO, 1999).

"Há dois tipos de disponibilidades: a disponibilidade máxima e a disponibilidade atual. A disponibilidade superficial máxima refere-se ao potencial de água de superfície da bacia medido na sua foz, do qual se deduz um índice médio de perdas por evaporação, representativo das condições hidroclimáticas regionais e das formas e dimensões dos represamentos. A disponibilidade atual corresponde ao somatório das capacidades de regularização dos reservatórios existentes atualmente na bacia. As disponibilidades de água subterrânea poderiam ser admitidas iguais ao potencial. Todavia, do escoamento de base dos rios e riachos de uma bacia, dependem, como se discorreu anteriormente, as demandas naturais de sistemas ecológicos (manguezais, por exemplo), fontes, etc. Assim sendo, as disponibilidades máximas de água subterrânea são iguais à diferença entre o potencial e as demandas naturais, aí incluídas as perdas por evaporação" (ALBUQUERQUE e RÊGO, 1999).

A disponibilidade hídrica superficial máxima representa, em volume ou vazão, a maior fração do potencial fluvial que pode ser disponibilizada para uso. Enquanto que, a disponibilidade atual corresponde à vazão fornecida pelos reservatórios já existentes que pode ser utilizada para diversos usos, consuntivos ou não, associada a certo nível de garantia ou a indicadores de desempenho (PARAÍBA, 2006).

O cálculo da potencialidade e da disponibilidade máxima superficial para a Bacia Sedimentar Costeira foi feito proporcionalmente à Região do Baixo Curso do rio Paraíba, obtidos em Paraíba (2006), apresentando valores de $4,72 \mathrm{~m}^{3} / \mathrm{s}$ e 2,84 $\mathrm{m}^{3} / \mathrm{s}$, respectivamente. Em relação às demandas, para a Região do Baixo Curso do rio Paraíba na sua parte Sedimentar, foi feita estimativa a partir do PERH para o ano de 2013. Nesta estimativa ficou excluída a área de 169,40 km² (João Pessoa e Cabedelo) quanto aos usos de irrigação e pecuária, por se tratarem de áreas urbanizadas. Para o restante da área $\left(939,29 \mathrm{~km}^{2}\right)$ considerou-se para irrigação, 0,83 $\mathrm{m}^{3} / \mathrm{s}$, e para a pecuária, $0,37 \mathrm{~m}^{3} / \mathrm{s}$. Para o abastecimento humano fez-se a proporção considerando que os principais reservatórios da bacia (Marés e São Salvador), os quais estão localizados na Bacia Sedimentar, seriam responsáveis por uma parte do abastecimento urbano e rural da grande João Pessoa, totalizando uma demanda de $0,40 \mathrm{~m}^{3} / \mathrm{s}$. Para a indústria foi considerada a demanda referente ao PERH (PARAÍBA, 2006) para o ano de 2013 de 0,84 $\mathrm{m}^{3} / \mathrm{s}$.

Para a determinação da potencialidade e da disponibilidade máxima superficial da Bacia Hidrográfica do rio Gramame foram utilizados os valores apresentados no PERH (PARAÍBA, 2006), os quais são: de $9,50 \mathrm{~m}^{3} / \mathrm{s}$ e $5,70 \mathrm{~m}^{3} / \mathrm{s}$, respectivamente. Em relação às demandas desta mesma bacia foram consideradas as apresentadas no PERH para o ano de 2013, com valor de $6,72 \mathrm{~m}^{3} / \mathrm{s}$, incluindo a demanda para abastecimento humano, irrigação, indústria e pecuária.

$\mathrm{Na}$ determinação das potencialidades, disponibilidade máxima e disponibilidade atual subter 
Tabela 1 - Demandas hídricas da região de estudo

\begin{tabular}{c|ccccc}
\hline & \multicolumn{4}{|c}{ Demandas $2013\left(\mathrm{~m}^{3} / \mathrm{s}\right) *$} \\
\cline { 2 - 6 } & Irrigação & $\begin{array}{c}\text { Abastecimento } \\
\text { humano }\end{array}$ & Indústria & Pecuária & Total \\
$\begin{array}{c}\text { Região do Baixo Curso } \\
\text { do rio PB }\end{array}$ & 3,46 & 0,72 & 0,84 & 1,57 & 6,59 \\
Bacia Sedimentar Costeira & 0,83 & 0,40 & 0,84 & 0,37 & 6,72 \\
Bacia do Gramame & 3,06 & 3,28 & 0,04 & 0,34 & 9,16 \\
\hline $\begin{array}{c}\text { Total (Bacia do Gramame }+ \\
\text { Bacia Sedimentar Costeira) }\end{array}$ & 3,89 & 3,68 & 0,88 & 0,71 \\
\hline
\end{tabular}

*As demandas foram obtidas do PERH (Paraíba, 2006)

Tabela 2 - Potencialidade, Disponibilidade e Demandas da região de estudo (Superficial e Subterrânea)

\begin{tabular}{|c|c|c|c|c|c|c|c|}
\hline & \multicolumn{2}{|c|}{ Potencialidade $\left(\mathrm{m}^{3} / \mathrm{s}\right)$} & \multicolumn{2}{|c|}{$\begin{array}{c}\text { Disponibilidade máxima } \\
\left(\mathrm{m}^{3} / \mathrm{s}\right)\end{array}$} & \multicolumn{2}{|c|}{$\begin{array}{l}\text { Disponibilidade } \\
\text { atual }\left(\mathrm{m}^{3} / \mathrm{s}\right)\end{array}$} & \multirow{2}{*}{$\begin{array}{c}\text { Totais das } \\
\text { Demandas para } \\
2013\left(\mathrm{~m}^{3} / \mathrm{s}\right)\end{array}$} \\
\hline & SUP. & SUB. & SUP. & SUB. & SUP. & SUB. & \\
\hline $\begin{array}{l}\text { Região do Baixo } \\
\text { Curso do rio PB }\end{array}$ & 16,70 & 4,57 & 10,07 & 3,17 & 0,28 & 2,30 & 6,59 \\
\hline $\begin{array}{c}\text { Bacia Sedimentar } \\
\text { Costeira }\end{array}$ & 4,72 & 1,29 & 2,84 & 0,89 & 0,28 & 0,65 & 2,44 \\
\hline Bacia do Gramame & 9,50 & 3,37 & 5,70 & 2,02 & 2,45 & 2,57 & 6,72 \\
\hline $\begin{array}{c}\text { Total (Bacia d } \\
\text { Gramame + Bacia } \\
\text { Sedimentar Costeira) }\end{array}$ & 14,22 & 4,66 & 8,54 & 2,91 & 2,73 & 3,22 & 9,16 \\
\hline
\end{tabular}

Fonte: Adaptado do PERH (Paraíba, 2006). SUP = superficial; SUB = subterrânea.

râneas das Bacias estudadas foram utilizados os valores apresentados no PERH (Paraíba, 2006).

As Tabelas 1 e 2 apresentam os valores para as demandas, potencialidade e disponibilidade hídrica máxima e atual da Bacia Sedimentar Costeira, inserida na Região do Baixo Curso do rio Paraíba e da Bacia do rio Gramame.

O modelo de simulação Acquanet (PORTO et al., 2003) foi utilizado para calcular a disponibilidade atual superficial da Bacia Sedimentar Costeira do Baixo Curso do rio Paraíba e da Bacia do rio Gramame.

Os Índices de Utilização das Disponibilidades Máxima e Atual (respectivamente, IUD $_{\mathrm{M}}$ e IU$\mathrm{D}_{\mathrm{A}}$ ) representam os níveis em que estarão e estão, respectivamente, sendo utilizadas as disponibilidades. São obtidos pela relação entre a demanda e a disponibilidade. Nesse contexto, observa-se que quanto mais próximo for o índice de 1, mais comprometida está a situação quantitativa dos recursos hídricos da região estudada. Conforme a Tabela 3, o $\mathrm{IUD}_{\mathrm{M}}$ para a região em estudo apresenta-se com

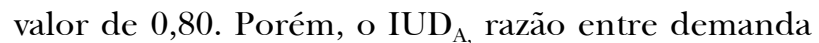
atual e disponibilidade atual, possui valores superiores a 1 , o que significa que a demanda total atual já compromete toda a região em análise, sendo necessárias medidas de gestão para mitigar essa situação.

Com relação ao Índice de Ativação das Disponibilidades Máximas $\left(\mathrm{IAD}_{\mathrm{M}}\right)$, que representa a relação entre a disponibilidade atual e a disponibilidade máxima, foram obtidos altos valores para o caso das águas subterrâneas. Tais valores indicam a crescente utilização da disponibilidade máxima na área de estudo. Considerando que o valor da área usada para a irrigação não foi objeto de atualização e que ela tem sido aumentada em função do aumento do plantio da cana de açúcar para obtenção do etanol, é possível que a explotação de água subterrânea, através de novas captações "a fio d'água”, tenha atingido o seu limite máximo, reforçando a tese do critério de uso prioritário das águas superficiais, pelo menos em bacias hidrográficas com as características das aqui estudadas. 
Tabela 3 - Índices de Utilização e Ativação da região de estudo

\begin{tabular}{ccccc}
\hline & & \multicolumn{2}{c}{ IAD $_{\mathrm{M}}$} \\
\cline { 3 - 5 } & $\operatorname{IUD}_{\mathrm{M}}$ & IUD $_{\mathrm{A}}$ & Superficial & Subterrânea* $^{*}$ \\
Região do Baixo Curso do rio Paraíba & 0,50 & 2,69 & 0,03 & 0,73 \\
Bacia Sedimentar Costeira & 0,65 & 3,54 & 0,10 & 0,73 \\
Bacia do Gramame & 0,87 & 1,44 & 0,43 & 1,27 \\
Total (Bacia do Gramame + Bacia Sedimentar Costeira) & 0,80 & 1,71 & 0,32 & 1,11 \\
\hline
\end{tabular}

Fonte: Adaptado do PERH (Paraíba, 2006)

$\mathrm{IUD}_{\mathrm{M}}$ - Índice de Utilização da Disponibilidade Máxima

$\mathrm{IUD}_{\mathrm{A}}$ - Índice de Utilização da Disponibilidade Atual

$\mathrm{IAD}_{\mathrm{M}}$ - Índice de Ativação da Disponibilidade Máxima

*Compreende, também, a captação a fio d'água

\section{Concepção do sistema de outorga pela retirada de água bruta de reservatórios superficiais}

Além de retirada de água de reservatórios, a outorga se destina à captação de água de superfície e subterrânea (poços, captações "a fio d'água”, de fontes, drenos, etc). Nestes casos, a vazão máxima outorgável é a disponibilidade máxima, superficial ou subterrânea, de uma bacia hidrográfica. Os componentes do sistema de outorga, a ser simulado para a área em estudo, estão descritos a seguir.

Vazões garantidas pelos reservatórios para determinação da vazão máxima outorgável

Tabela 4 - Vazões máximas outorgáveis dos reservatórios superficiais em $\mathrm{m}^{3} / \mathrm{s}$

\begin{tabular}{llcc}
\hline Reservatórios & \multicolumn{3}{l}{ Vazão/Garantia $\left(\mathrm{m}^{3} / \mathrm{s}\right)$} \\
\cline { 2 - 4 } & $100 \%$ & $95 \%$ & $90 \%$ \\
Gramame-Mamuaba & 2,45 & 3,26 & 3,60 \\
Marés & 0,22 & 0,32 & 0,37 \\
São Salvador & 0,05 & 0,10 & 0,13 \\
\hline
\end{tabular}

Para o caso em estudo, a vazão máxima outorgável é definida através da curva de garantia dos reservatórios. Desta curva retiram-se os valores das disponibilidades superficiais garantidas com 100\%, $95 \%$ e $90 \%$. As vazões regularizadas dos reservatórios em estudo foram determinadas pelo modelo Acquanet (PORTO et al., 2003). As séries de vazões afluentes utilizadas nas simulações para determinar a vazão regularizada dos açudes foram geradas pelo modelo hidrológico chuva-vazão MODHAC (LANNA e SCHWARZBACH, 1989). A Tabela 4 apresenta as vazões máximas outorgáveis dos reservatórios Marés, Gramame-Mamuaba e São Salvador.

\section{Definição da vazão máxima outorgável}

Uma metodologia para a definição da vazão outorgável (vazão de referência) é estabelecer um valor de vazão em cada estação do ano que passa a representar o limite superior de utilização do curso d'água. Esta vazão de referência é, então, aceita como a vazão máxima outorgável sazonalmente (PAIVA e RIBEIRO, 2000). Há uma extensa discussão sobre a temática da vazão de referência para a outorga podendo ser citados os trabalhos de Silva e Lanna (1996), Ferraz e Braga (1998), Câmara e Lanna (2002), Câmara (2003), Ribeiro e Lanna (2003), Ramos (2005), Silva et al (2006), Fioreze et al (2008), Curi et al (2011).

No Brasil, duas referências muito usadas são (PAIVA e RIBEIRO, 2000):

- Vazão de referência como a média das vazões de 7 dias consecutivos da estiagem com tempo de retorno de 10 anos $\left(Q_{7,10}\right)$.

- Vazões de referência definidas pela estimativa da curva de permanência das vazões naturais; curva que relaciona cada vazão à frequência com que foi igualada ou ultrapassada no período de tempo de observações. Um exemplo é a $Q_{90}$, vazão cuja probabilidade de superação é de $90 \%$.

Observa-se que, na área de estudo, as vazões de permanência e a $Q_{7,10}$ são, eminentemente, águas subterrâneas responsáveis pelo fluxo de base que, de tão pequenas nessas bacias hidrográficas e hidrogeológicas costeiras e sedimentares, não são suficientes para o atendimento de maiores demandas, principalmente dos grandes projetos de irrigação. Haverá, portanto, a necessidade de intervenção humana 
(vazão regularizada) para a construção de estruturas de captação, mormente das águas superficiais, já que a disponibilidade máxima de águas subterrânea é, igualmente, exígua.

As vazões de referência de alta garantia podem ser totalmente oriundas do suprimento subterrâneo. Frequentemente são, mesmo, as de $95 \%$ de garantia. Para saber, basta comparar com a vazão média anual do escoamento subterrâneo, dada pela vazão de base (bacias hidrogeológicas interioranas) e pela vazão de base acrescida da vazão escoada diretamente ao oceano (bacias hidrogeológicas costeiras). No caso em apreço, a vazão de base ou o potencial de água subterrânea das bacias hidrográficas dos rios Paraíba (Baixo Curso) e Gramame foram estimadas (Paraíba, 2006) em 4,57 $\mathrm{m}^{3} / \mathrm{s}$ e 3,37 $\mathrm{m}^{3} / \mathrm{s}$, confirmando que as vazões de referência outorgáveis $\left(Q_{95}\right)$ são originárias do escoamento subterrâneo.

Após a definição da vazão de referência, uma parte da mesma é outorgada e a outra é destinada à manutenção dos processos ecológicos ou ao atendimento de demandas já outorgadas a jusante. Estas metodologias não são de todo aplicáveis às bacias, dimensional e hidrologicamente pequenas, porque restringem muito a oferta de recursos hídricos. Nestes casos, o valor de referência é a descarga regularizada anual, com uma certa garantia, de reservatórios superficiais. No Estado da Paraíba, a garantia preconizada pela legislação vigente é de $90 \%$, quando se tratar de água superficial, o que significa que existe um risco de, em $10 \%$ dos anos, desta descarga ser menor ou mesmo nula. Por esta razão, a garantia, principalmente para os usos prioritários, teria que ser $100 \%$. E ainda há uma possibilidade de falha, já que as séries de dados hidrológicos são curtas e apresentam pouca confiabilidade estatística.

\section{Equacionamento do sistema de outorga}

A equação (1) a seguir apresenta o equacionamento do sistema de outorga (PAIVA e RIBEIRO, 2000):

$\sum_{\mathrm{i}, \mathrm{j}}\left[\left(\alpha_{\mathrm{i}}\right) \cdot\right.$ Qcapta $\left._{\mathrm{i}, \mathrm{j}}\right] \leq$ Qmáx outorgável ${ }_{\mathrm{j}}$

Se $\left[\left(\alpha_{\mathrm{i}}\right)\right.$. Qcapta Q $\left._{\mathrm{i}, \mathrm{j}}\right]<$ Qmáx outorgável ou $_{\mathrm{j}} \Rightarrow\left[\left(\alpha_{\mathrm{i}}\right)\right.$. Qcapta $\left._{\mathrm{i}, \mathrm{j}}\right]=$ Qoutorgada $_{\mathrm{i}, \mathrm{j}}$.

Se $\left[\left(\alpha_{\mathrm{i}}\right)\right.$. Qcapta $\left._{\mathrm{i}, \mathrm{j}}\right] \geq$ Qmáx outorgável $_{\mathrm{j}} \Rightarrow$ Qoutor$\operatorname{gada}_{\mathrm{i}, \mathrm{j}}=$ Qmáx outorgável $_{\mathrm{j}}$.
Com Qmáx outorgável ${ }_{\mathrm{j}}=0,9 . \mathrm{Q}_{90}$ e Qecológica $_{\mathrm{j}}=$ 0,1. $Q_{90}$.

\section{Sendo:}

Qcapta $_{\mathrm{i}, \mathrm{i}}$ - a vazão captada pelo usuário i na seção j definida pelo reservatório;

$\alpha$ - o coeficiente de uso da vazão de captação do usuário i (igual a unidade neste estudo);

$Q_{\text {máx outorgávelj }}$ - a vazão máxima outorgável na seção j;

$Q_{\text {outorgadai,j }}$ - a vazão outorgada ao usuário i na seção j;

$\mathrm{Q}_{90}$ - a vazão de referência;

$\mathrm{Q}_{\text {ecológica }}$ - a vazão ecológica; todas as vazões $\mathrm{em} \mathrm{m}^{3} / \mathrm{s}$.

Para avaliar o comportamento do sistema de outorga calcula-se o percentual de falha (frequência), uma falha é entendida como uma impossibilidade de atendimento à demanda requerida e ocorre sempre que essa demanda for superior à vazão máxima outorgável para o Ponto de Controle em análise, isto é:

$\left[\left(\alpha_{\mathrm{i}}\right) \cdot Q_{\text {captai, } \mathrm{j}}\right]>Q_{\text {máx outorgávelj }} \Rightarrow Q_{\text {não atendida } \mathrm{i}, \mathrm{j}}=\left[\left(\alpha_{\mathrm{i}}\right)\right.$. $\left.Q_{\text {captai, } j}\right]-Q_{\text {máx outorgávelj. }}$.

Sendo $Q_{\text {não atendida i, j, a parte da vazão requerida que }}$ não é atendida. Ressaltando que para este estudo foram utilizadas como vazão de referência a $Q_{90}, Q_{95}$ e a $Q_{100}$. Desta forma, para todas as vazões de referência foi mantida a QMax outorgável igual $90 \%$ da Q90. Destaca-se também que a disponibilidade subterrânea não foi introduzida no modelo.

\section{RESULTADOS E DISCUSSÃO}

Foram feitas duas análises para verificação do critério de prioridade de uso das águas superficiais, sendo uma delas com base na vazão regularizada (disponibilidade atual) e a outra na disponibilidade hídrica máxima da região em estudo (esta baseada em PARAÍBA, 2006).

\section{Análise 1 - Vazão máxima outorgável com base nas vazões regularizadas}

O objetivo foi verificar se os reservatórios Marés, Gramame-Mamuaba e São Salvador atendiam às demandas solicitadas, caso contrário utilizar-seíam as águas subterrâneas, se estas ainda apresentassem saldo de disponibilidades.

$\mathrm{Na}$ Simulação 1 foram consideradas as vazões $Q_{90}, Q_{95}$ e $Q_{100}$ e, neste caso, as vazões solicita 
Tabela 5 - Simulação 1 - Reservatório Marés

\begin{tabular}{|c|c|c|c|c|}
\hline \multicolumn{5}{|c|}{ Reservatório Marés } \\
\hline Vazão regularizada $Q_{90}$ & *Vazão Requerida $\left(\mathrm{m}^{3} / \mathrm{s}\right)$ & $\begin{array}{c}\text { Vazão Máxima } \\
\text { Outorgável }\left(\mathrm{m}^{3} / \mathrm{s}\right)\end{array}$ & $\begin{array}{l}\text { Vazão outorgada } \\
\qquad\left(\mathrm{m}^{3} / \mathrm{s}\right)\end{array}$ & $\begin{array}{c}\text { Atendimento } \\
(\%)\end{array}$ \\
\hline 0,368 & 1,854 & 0,331 & 0,331 & 17,86 \\
\hline Vazão regularizada $Q_{95}$ & *Vazão Requerida $\left(\mathrm{m}^{3} / \mathrm{s}\right)$ & $\begin{array}{c}\text { Vazão Máxima } \\
\text { Outorgável }\left(\mathrm{m}^{3} \text { /s) }\right.\end{array}$ & $\begin{array}{l}\text { Vazão outorgada } \\
\qquad\left(\mathrm{m}^{3} / \mathrm{s}\right)\end{array}$ & $\begin{array}{c}\text { Atendimento } \\
(\%)\end{array}$ \\
\hline 0,320 & 1,854 & 0,288 & 0,288 & 15,53 \\
\hline $\begin{array}{l}\text { Vazão regularizada } \\
\qquad Q_{100}\end{array}$ & *Vazão Requerida $\left(\mathrm{m}^{3} / \mathrm{s}\right)$ & $\begin{array}{c}\text { Vazão Máxima } \\
\text { Outorgável }\left(\mathrm{m}^{3} / \mathrm{s}\right)\end{array}$ & $\begin{array}{l}\text { Vazão outorgada } \\
\qquad\left(\mathrm{m}^{3} / \mathrm{s}\right)\end{array}$ & $\begin{array}{c}\text { Atendimento } \\
(\%)\end{array}$ \\
\hline 0,222 & 1,854 & 0,200 & 0,200 & 10,77 \\
\hline
\end{tabular}

*Vazão requerida = valores de demandas do PERH (Paraíba, 2006).

Tabela 6 - Simulação 1 - Reservatório Gramame-Mamuaba

\begin{tabular}{|c|c|c|c|c|}
\hline \multicolumn{5}{|c|}{ Reservatório Gramame-Mamuaba } \\
\hline Vazão regularizada $Q_{90}$ & $\begin{array}{c}\text { *Vazão Requerida } \\
\left(\mathrm{m}^{3} / \mathrm{s}\right)\end{array}$ & $\begin{array}{c}\text { Vazão Máxima } \\
\text { Outorgável }\left(\mathrm{m}^{3} \text { /s) }\right.\end{array}$ & $\begin{array}{l}\text { Vazão outorgada } \\
\qquad\left(\mathrm{m}^{3} / \mathrm{s}\right)\end{array}$ & $\begin{array}{c}\text { Atendimento } \\
(\%)\end{array}$ \\
\hline 3,600 & 6,718 & 3,240 & 3,240 & 48,23 \\
\hline Vazão regularizada $Q_{95}$ & $\begin{array}{c}\text { *Vazão Requerida } \\
\left(\mathrm{m}^{3} / \mathrm{s}\right)\end{array}$ & $\begin{array}{c}\text { Vazão Máxima } \\
\text { Outorgável }\left(\mathrm{m}^{3} / \mathrm{s}\right)\end{array}$ & $\begin{array}{l}\text { Vazão outorgada } \\
\qquad\left(\mathrm{m}^{3} / \mathrm{s}\right)\end{array}$ & $\begin{array}{c}\text { Atendimento } \\
(\%)\end{array}$ \\
\hline 3,260 & 6,718 & 2,932 & 2,932 & 43,65 \\
\hline Vazão regularizada $Q_{100}$ & $\begin{array}{c}\text { *Vazão Requerida } \\
\left(\mathrm{m}^{3} / \mathrm{s}\right)\end{array}$ & $\begin{array}{c}\text { Vazão Máxima } \\
\text { Outorgável }\left(\mathrm{m}^{3} / \mathrm{s}\right)\end{array}$ & $\begin{array}{l}\text { Vazão outorgada } \\
\qquad\left(\mathrm{m}^{3} / \mathrm{s}\right)\end{array}$ & $\begin{array}{c}\text { Atendimento } \\
(\%)\end{array}$ \\
\hline 2,450 & 6,718 & 2,205 & 2,205 & 32,82 \\
\hline
\end{tabular}

*Vazão requerida = vazões de demandas do PERH (Paraíba, 2006).

Tabela 7 - Simulação 1 - Reservatório São Salvador

\begin{tabular}{|c|c|c|c|c|}
\hline \multicolumn{5}{|c|}{ Reservatório São Salvador } \\
\hline Vazão regularizada $Q_{90}$ & *Vazão Requerida $\left(\mathrm{m}^{3} / \mathrm{s}\right)$ & $\begin{array}{c}\text { Vazão Máxima } \\
\text { Outorgável }\left(\mathrm{m}^{3} \text { /s) }\right.\end{array}$ & $\begin{array}{l}\text { Vazão outorgada } \\
\qquad\left(\mathrm{m}^{3} / \mathrm{s}\right)\end{array}$ & $\begin{array}{c}\text { Atendimento } \\
(\%)\end{array}$ \\
\hline 0,133 & 0,293 & 0,120 & 0,120 & 40,83 \\
\hline Vazão regularizada $Q_{95}$ & *Vazão Requerida $\left(\mathrm{m}^{3} / \mathrm{s}\right)$ & $\begin{array}{c}\text { Vazão Máxima } \\
\text { Outorgável }\left(\mathrm{m}^{3} \text { /s) }\right.\end{array}$ & $\begin{array}{l}\text { Vazão outorgada } \\
\qquad\left(\mathrm{m}^{3} / \mathrm{s}\right)\end{array}$ & $\begin{array}{c}\text { Atendimento } \\
(\%)\end{array}$ \\
\hline 0,103 & 0,293 & 0,093 & 0,093 & 31,66 \\
\hline Vazão regularizada $Q_{100}$ & *Vazão Requerida $\left(\mathrm{m}^{3} / \mathrm{s}\right)$ & $\begin{array}{c}\text { Vazão Máxima } \\
\text { Outorgável }\left(\mathrm{m}^{3} / \mathrm{s}\right)\end{array}$ & $\begin{array}{l}\text { Vazão outorgada } \\
\qquad\left(\mathrm{m}^{3} / \mathrm{s}\right)\end{array}$ & $\begin{array}{c}\text { Atendimento } \\
(\%)\end{array}$ \\
\hline 0,054 & 0,293 & 0,049 & 0,049 & 16,60 \\
\hline
\end{tabular}

*Vazão requerida = vazões de demandas do PERH (Paraíba, 2006)

Tabela 8 - Simulação 2 - Atendimento às demandas utilizando as disponibilidades superficiais

\begin{tabular}{cccc}
\hline Bacias & $\begin{array}{c}\text { Vazão Requerida* } \\
\left(\mathrm{m}^{3} / \mathrm{s}\right)\end{array}$ & $\begin{array}{c}\text { Disponibilidade } \\
\text { Hídrica }\left(\mathrm{m}^{3} / \mathrm{s}\right)\end{array}$ & $\begin{array}{c}\text { Atendimento às demandas utilizando a } \\
\text { disponibilidade }(\%)\end{array}$ \\
\hline Baixo Curso rio Paraíba & 6,59 & 10,07 & 152,81 \\
Sedimentar Costeira & 2,15 & 2,84 & 132,27 \\
Gramame & 6,72 & 5,70 & 84,85 \\
\hline
\end{tabular}

*Vazão requerida = vazões de demandas do PERH (Paraíba, 2006). 
das foram maiores do que as vazões outorgáveis, havendo falha no atendimento às demandas. O reservatório Marés apresentou a situação mais crítica no atendimento às demandas em relação aos demais reservatórios, ao considerar as vazões regularizadas $\mathrm{Q}_{90}, \mathrm{Q}_{95}$ e $\mathrm{Q}_{100}$. Os percentuais para suprir as demandas através de água subterrânea são $82,14 \%$, $84,47 \%$ e $89,23 \%$ respectivamente. A Tabela 5 apresenta a garantia para atendimento das demandas a partir desse reservatório, a qual se apresenta comprometida.

Para o reservatório Gramame-Mamuaba utilizando-se as vazões regularizadas $Q_{90}, Q_{95}$ e $Q_{100}$, os percentuais de água subterrânea necessários para atender as demandas são de $51,77 \%, 56,35 \%$ e $67,18 \%$ respectivamente (Tabela 6 ).

Para o reservatório São Salvador utilizandose as vazões regularizadas $Q_{90}, Q_{95}$ e $Q_{100}$ seriam necessários incrementos de água subterrânea (59,17\%; $68,34 \% ; 83,40 \%$, respectivamente (Tabela 7)).

\section{Análise 2 - Ativação da disponibilidade hídrica máxima da área de estudo}

Com os resultados da análise 1 verificou-se que não houve atendimento às demandas solicitadas.

Neste sentido foi analisada a disponibilidade hídrica máxima superficial da região em estudo, com o intuito de averiguar a possibilidade de atendimento às demandas, ou seja, ativar o uso água superficial disponível, sem que explore o uso das águas subterrâneas (Tabela 8).

A partir dos resultados obtidos na análise 2, observa-se que as demandas seriam plenamente atendidas para a Bacia Sedimentar Costeira do Baixo Curso do rio Paraíba. Para a Bacia do rio Gramame, o atendimento às demandas estaria comprometido em $15,15 \%$. Todavia, a disponibilidade de água subterrânea, nas bacias dos rios Paraíba e Gramame, está se aproximando da exaustão (ou já está exaurida). Entendendo-se que se faz necessário atender novos pedidos de outorga, um rigoroso estudo sobre o quão eficiente é (ou não é) o uso da água na região em estudo deve ser considerado. Neste sentido, ressalta-se que este estudo se trata de uma análise global de disponibilidade na bacia. Alternativas de Gerenciamento da Demanda de Água (GDA) devem ser propostas a fim de verificar as possibilidades de aumento da oferta (GUEDES, 2008; BARROS, 2013).

\section{CONGLUSÕES}

A prioridade de uso das águas superficiais, utilizada como critério neste artigo, demonstrou que o abastecimento humano não pode ser atendido com a utilização das águas, atualmente acumuladas nos reservatórios da área estudada, quando considerada a vazão máxima outorgável.

Com a ativação da disponibilidade hídrica remanescente até atingir a disponibilidade máxima, observou-se que, para a Bacia Sedimentar Costeira do Baixo Curso do rio Paraíba as demandas seriam plenamente atendidas pelos dois segmentos. Entretanto, para a Bacia Hidrográfica do rio Gramame, o atendimento da demanda ainda estaria comprometido. Sugere-se averiguar as possibilidades do Gerenciamento da Demanda de Água como alternativa para o aumento da oferta de água na região em estudo e não, apenas, a tradicional ótica da simples expansão da oferta (construção de novos reservatórios e ou importação de água de bacias hidrográficas vizinhas).

A metodologia adotada neste trabalho permitiu verificar se a disponibilidade de água superficial em uma bacia hidrográfica é suficiente para o atendimento de novas demandas ou não. Permitiu, também, constatar se há recursos hídricos superficiais remanescentes, os quais devem ser ativados por quem de direito, para o seu suprimento, sem uso imediato das águas subterrâneas a serem preservadas por sua função estratégica para o regime dos rios e o meio ambiente.

\section{AGRADECIMENTOS}

Esta pesquisa se insere no âmbito do projeto "Integração dos instrumentos de outorga, enquadramento e cobrança para a gestão das águas subterrâneas" o qual foi financiado pelo MCT/FINEP/CT-HIDRO. A primeira autora recebeu bolsa do CNPq no Programa de Pós Graduação em Engenharia Civil e Ambiental da UFCG. O quarto autor teve bolsa financiada pelo referido projeto. Os autores agradecem a todas as instituições mencionadas.

\section{REFERÊNCIAS}

ALBUQUERQUE, J. do P. T.; RÊGO, J. C. (1999). Subsídios para o gerenciamento racional e integrado dos recursos hídri- 
cos superficiais e subterrâneos do estado da Paraíba. In: XIII Simpósio Brasileiro de Recursos Hídricos. Porto Alegre: AB$\mathrm{RH}$.

ASUB (2010) Integração dos instrumentos de outorga, enquadramento e cobrança para a Gestão das águas Subterrâneas. Relatório Técnico Parcial $n^{0} 2$. Campina Grande: Universidade Federal de Campina Grande.

BARROS, M. de B. (2013). Avaliação de mecanismos poupadores de água como suporte ao planejamento urbano em Campina Grande-PB. Dissertação de Mestrado. Programa de Pós-graduação em Engenharia Civil e Ambiental. Universidade Federal de Campina Grande. Campina Grande.

CAGEPA (2011). Companhia de Água e Esgotos da Paraíba. Unidade de Negócios da Borborema. Comunicação Interna.

CÂMARA, A. C. F. C., LANNA, A. E. L. (2002). Proposta para análise da vazão máxima outorgável e da introdução simplificada da qualidade da água no processo de outorga da bacia do rio Gramame. In: VII Simpósio de Recursos Hídricos do Nordeste. ABRH: Maceió.

CÂMARA, A. C. F. C. (2003). Análise da vazão máxima outorgável e da introdução simplificada da qualidade da água no processo de outorga da bacia do rio Gramame -PB. Dissertação de Mestrado. IPH - Porto Alegre, Universidade Federal do Rio Grande do Sul.

COSTA, M. L. M; RIBEIRO, M. M. R.; RÊGO, J. C.; ALBUQUERQUE, J. do P. T (2011) Proposição de critérios de outorga para águas subterrâneas. Revista Brasileira de Recursos Hídricos RBRH, v. 16, n. 1, p. 105-113.

CURI, W. F.; CELESTE, A. B.; CURI, R. C.; RODRIGUES, A. C. L. (2011). Um Modelo de outorga para bacias controladas por reservatórios: 1 - Desenvolvimento do modelo que contempla demandas múltiplas e variáveis mensalmente. RBRH Revista Brasileira de Recursos Hídricos, . v. 16, n.4, p. 73-82.

CRUZ, J. C. e TUCCI, C. E. M. (2005).Otimização e simulação comparativa de cenários de outorga. RBRH - Revista Brasileira de 2005, v. 10, n. 3, p. 75-91.

FONSECA, F. (2008). Efeitos do turismo na demanda d'água da bacia do rio Gramame - estudo de caso. Dissertação de Mestrado. Curso de Pós-Graduação em Engenharia Civil e Ambiental, Universidade Federal de Campina Grande, Campina Grande, p 143.

FERRAZ, A. R. G., BRAGA JR, P. F. (1998). Modelo decisório para a outorga de direito ao uso da água no Estado de São
Paulo. RBRH - Revista Brasileira de Recursos Hídricos, v. 3 , n. 1, p. 5-19.

FIOREZE, A.P.;OLIVEIRA, L. F. C. de; FRANCO, A. P. B. (2008). Avaliação do desempenho de equações de regionalização de vazões na bacia hidrográfica do Ribeirão Santa Bárbara, Goiás, Brasil. Revista Ambiente e Água. Vol. n.2. p. 62-76.

FRANTZ, L. C. e CRUZ, J. C. (2010). O processo de outorga de direito de uso de recursos hídricos supericiais no Rio Grande do Sul: contribuições para o aprimoramento. REGA - Revista de Gestão de Água da América Latina, v.17, n. 1. p.5-16.

GUEDES, M. J. F. (2009) Gerenciamento da demanda de água: proposta de alternativas na escala de uma cidade. Dissertação de Mestrado. Programa de Pós-graduação em Engenharia Civil e Ambiental. Universidade Federal de Campina Grande. Campina Grande.

LANNA, A. E.; SCHWARZBACH, M. (1989) MODHAC - Modelo Hidrológico Auto-calibrável. Instituto de Pesquisas Hidráulicas da UFRGS. 55p. (Recursos Hídricos Publicação n. 21).

PAIVA, A. E. D., RIBEIRO, M. M. R. (2000).Outorga dos direitos de uso da água na bacia do rio Gramame-PB. In: Anais do IV Simpósio de Recursos Hídricos do Nordeste. Natal: ABRH.

PARAÍBA (2006). Plano Estadual de Recursos Hídricos do Estado da Paraíba PERH. Relatório Final.

PORTO, R. L. L.; ROBERTO, A. N.; SCHARDONG, A.; MÉLLO JÚNIOR, A.V. (2003). Sistema de suporte a decisão para análise de sistemas de recursos hídricos. In: Silva, R. C. V. Métodos numéricos em recursos hídricos. Porto Alegre: $A B-$ RH. Cap.2, p.93-240.

RAMOS, P. R. (2005). Modelo de outorga de uso da água utilizando a metodologia multicritério de apoio à decisão: estudo de caso da bacia hidrográfica do rio Cubatão do Sul. Tese de Doutorado. Florianópolis: Universidade Federal de Santa Catarina.

RIBEIRO, M. M. R., LANNA, A. E A (2003). Outorga integrada das vazões de captação e diluição. Revista Brasileira de Recursos Hídricos RBRH, v. 6, n. 4, p. 41-70.

SEMARH. (2000). Plano Diretor da Bacia Hidrográfica do Rio Gramame. Secretaria Extraordinária do Meio Ambiente, dos Recursos Hídricos e Minerais do Estado da Paraíba. Convênio SEMARH/SCIENTEC. Volumes 1, 2, 3 e 4. 
SILVA, L. M., LANNA, A. E. (1996). A outorga dos direitos de uso da água no cerrado baiano. In: III Simpósio de Recursos Hídricos do Nordeste. Salvador: ABRH.

SILVA, A. M. da; OLIVEIRA, P. M. de; MELLO, C. R. de; PIERANGELI, C. (2006). Vazões mínimas e de referência para outorga na região do Alto Rio Grande, Minas Gerais. Revista Brasileira de Engenharia Agrícola e Ambiental, v.10, n.2, p.374-380.

Simulation Of Surface Water Use Priority As A Criterion For Water Rights

\section{ABSTRACT}

This paper aims at simulating a criterion for the concession of water rights which considers surface water availability as a priority. It means that surface water must be used and groundwater must be preserved. The ParaibaPernambuco Coastal Sedimentary Basin in the Lower Course Region of the Paraíba River Basin and the Gramame River Basin (both located in Paraiba State, Brazil) were selected as case studies. Considering this criterion, groundwater should be preserved for its strategic role (to maintain the regime of rivers and the environment).

Key-words: Water rights; Groundwater; Integrated water resources management. 